\title{
LO “IRREAL” EN XAVIER ZUBIRI: EL PROBLEMA FILOSÓFICO DEL ARTE Y LA LITERATURA (A LA LUZ DE J. R. R. TOLKIEN)*
}

Diego Honorato E. Universidad de los Andes dhonorato@uandes.cl

\begin{abstract}
RESUMEN / ABSTRACT
En este artículo se aborda el problema de lo irreal en el filósofo español Xavier Zubiri y, más específicamente, el problema de la ficción y del arte. Se realiza una breve conceptuación de lo que el filósofo entiende por realidad, y de cómo se inserta en ella lo irreal. Se propone sucintamente que lo irreal es "realmente" irreal y que el hombre está forzado a habérselas con lo irreal y con la ficción para poder estar verdaderamente en las cosas. El artículo, al modo de un estudio de caso, pone en diálogo lo previamente expuesto con la concepción tolkieniana de la fantasía.
\end{abstract}

Palabras Clave: Zubiri, realidad, irreal, ficción, obra de arte, Tolkien.

\section{THE "UNREAL" IN XAVIER ZUBIRI: THE PHILOSOPHICAL PROBLEM OF ART AND LITERATURE (IN THE LIGHT OF J. R. R. TOLKIEN)}

In this article it is studied the problem of the 'unreal' in the Spanish philosopher Xavier Zubiri. More specifically we deal with the problem of fictions and art. A brief conceptualization is made about what the philosopher understands by reality, and how the unreal is inserted in it. It is briefly proposed that the unreal is "really" unreal and that man is forced or compelled to deal with the unreal and with fictions in order to be able to actually and truly be with (amid) real things. The article, as if were a case study, establishes a dialogue between the previous views and the tolkeinian conception of phantasy.

KEYWORDS: Zubiri, reality, unreal, fiction, work of art, Tolkien.

El presente artículo se inscribe en el marco del proyecto de investigación Fondecyt de iniciación número 11140325. 
"Probablemente, todo escritor, todo sub-creador que elabora un mundo secundario, una fantasía, desea en cierta medida ser un verdadero creador, o bien tiene la esperanza de que [...] la índole típica de ese mundo secundario proceda de la realidad o fluya hacia ella. Si de verdad consigue una cualidad a la que justamente se le pueda aplicar la definición del diccionario, 'consistencia interna de la realidad', es difícil entonces concebir que la haya logrado sin que la obra forme parte de esa realidad" (J. R. R. Tolkien, Sobre los Cuentos de Hadas, 188).

R⿴囗十 "Toda obra de arte auténtica, aun la más pequeña, lleva adherido el mundo; un ámbito conformado, lleno de contenido de sentido, en que se puede penetrar mirando, oyendo, moviéndose [...]. La obra de arte [...] abre un espacio en que el hombre puede entrar, respirar, moverse y tratar con las cosas y personas que se han hecho patentes" (Guardini 1981: 322-323). Estas palabras, que fueron expresadas en la Academia de Artes Plásticas de Stuttgart el año 1947, por el pensador cristiano Romano Guardini, reflejan una experiencia tremendamente afín a la concepción tolkieniana que se expresa en el epígrafe, y que tanto artistas en general como también quienes contemplan una obra de arte dicen experimentar. La obra de arte, una realidad de ficción, parece presentarse y hacernos patente desde sí misma un mundo singular, un espacio o un ámbito sui generis "en que -como expresa Guardini- el hombre puede entrar, respirar, moverse y tratar con las cosas y personas que se han hecho patentes"'. Pues bien, este breve artículo, tomándose muy en serio estas palabras, quisiera intentar dar cuenta y explicar desde la perspectiva de la filosofía del pensador español Xavier Zubiri cómo es esto posible. En pocas palabras no resulta para nada evidente cómo es que una obra de arte, una articulación unitaria de sentidos ficticios aprehendida por la conciencia puede ser experimentada como una cosa o ámbito cuasi-real en el cual yo puedo libremente entrar o salir como si se tratara del espacio físico en el cual estoy ahora instalado. Para hacernos cargo de este problema, sin embargo, será necesario hacer un periplo por la filosofía de Zubiri ${ }^{2}$ concentrándonos en el problema de lo "irreal” en el cual, según Zubiri, estaría incardinada la cuestión de la obra de ficción.

\section{Cfr. supra.}

Nos remitiremos en este artículo a dos obras de Zubiri que presentamos aquí ordenadamente según el mayor o menor uso que haremos de éstas: Xavier Zubiri (2005), El Hombre: Lo Real y lo Irreal, Madrid: Alianza (de aquí en adelante citado como HRI). Se trata de un curso que Zubiri impartió entre febrero y marzo de 1967; Xavier Zubiri (1982), Inteligencia y Logos, Madrid: Alianza (de aquí en adelante citado como $I L$; véase particularmente el parágrafo tres del cap. IV, "Estructura de lo aprehendido en distancia", donde se encuentran las posiciones últimas de Zubiri). Aunque no citaremos directamente la obra Sobre el Hombre, ésta también contiene algunas páginas importantes que quizás el lector quiera 
Siguiendo el hilo argumentativo que se encuentra en El Hombre: Lo Real y lo Irreal (1967), así como los planteamientos que Zubiri elabora en Inteligencia Sentiente (1980-1983), examinaremos estas cuestiones en dos pasos sucesivos: 1. ¿Qué es lo irreal y cuáles son sus modos? 2. La ficción y el arte como modo de lo irreal. 3. Un caso literario: la concepción de la fantasía en J. R. R. Tolkien.

\section{1. ¿Qué es lo irreal y cuáles son sus modos?}

El problema de lo irreal y de la irrealidad en que, como veremos, se inserta la cuestión de la ficción, no puede sino ser pensado, nos dice Zubiri, al hilo de una determinada conceptuación de lo que se entienda por lo "real". Pues si es cierto que lo "irreal", como lo señala su prefijo, ha de estar en una relativa oposición con su otro polo, lo "real", entonces, quizás, la forma más expedita de establecer lo que se entienda por irreal sea partir por su contraconcepto. Sin embargo, antes de esclarecer cuál es la posición de Zubiri en estas cuestiones, intentaremos como análisis preparatorio -el filósofo mismo así lo hace en $H R I$ - despejar el camino aludiendo brevemente a las tesis defendidas por el pensamiento escolástico. La escolástica tardía, en efecto, suele pensar la cuestión de lo irreal, aunque no utilizara esa categoría, aludiendo a la distinción entre aquello que posee una existencia actual, extra-animan, y que tiene, por tanto, un ser o existir real, un esse reale, y aquellas otras entidades que poseerían, en cambio, un modo de existencia intra-animam, y que al modo de una idea o una quimera, poseerían tan solo un ser intencional, un esse intentionale (o esse spirituale) ${ }^{3}$. Asimismo distinguieron entre diversos tipos de ideas según si poseían algún fundamento in re o no. Así, por ejemplo, la idea de un árbol, poseería un esse intentionale en el entendimiento, pero al mismo tiempo tendría un fundamento en la cosa que está allí afuera, es decir, un fundamento in re; no obstante, habría, también, otro tipo de ideas, como puede ser el caso de una quimera, un centauro, que no tendrían un fundamento en nada real externo, es decir, serían, desde nuestra perspectiva, para efectos de este trabajo, "irreales". La escolástica, de este modo, sostendría que una quimera (algo irreal) tendría un mero carácter carencial, sería un nihilum existentiae, es decir, una cierta entidad deficitaria que aunque poseería una quidditas, una esencia en el entendimiento cada vez que es pensada o imaginada, no tendría, propiamente hablando, existencia. Ahora bien, Zubiri

consultar. Cfr. Xavier Zubiri (1998), Sobre el Hombre, Madrid: Alianza: 644-657 (estas páginas corresponden al curso oral "El Problema del Hombre" (1953-1954)).

3 Tomás de Aquino, por ejemplo, no usa la expresión esse reale (que Zubiri utiliza), pero sí distingue entre esse naturale y esse intentionale. Aunque no son muchos los pasajes donde lo hace su importancia es fundamental para comprender la gnoseología tomista. Al respecto, véase, Tomás de Aquino, Liber II De Anima, cap., 24, 54-56; también S. Th, I, 56, 2, ad 3. Para un mirada comprehensiva de esta cuestión en el aquinate véase Moya, Patricia. "La intencionalidad como elemento clave en la gnoseología del Aquinate". Pamplona: Cuadernos de Anuario Filosófico, 2000. 
cree que este planteamiento es insuficiente y que falsea el problema de lo irreal, porque en su raíz no ha captado correctamente la cuestión más ardua: la realidad. Por eso, antes de entrar derechamente en el problema de la irrealidad en Zubiri, se hace necesario decir algunas palabras en torno a su novísima concepción de la realidad, aun cuando lo que pueda decirse aquí será objetivamente muy poco, teniendo en vista la complejidad de la posición zubiriana ${ }^{4}$.

Zubiri piensa que la realidad no es "algo" que está delante, sino un carácter o una formalidad -como él la llama- de la cosa real que, desde la perspectiva de la intelección, consiste en un modo de habérselas con las cosas en la aprehensión en tanto que reales qua reales. Por esto a diferencia del animal, que aprehende en la percepción ciertas notas o contenidos al modo de un estímulo que gatilla un proceso en el sentir del animal (es el circuito cerrado "estímulo-modificación tónica-respuesta"), Zubiri piensa que el hombre aprehende las mismas notas respectivas -aunque esto dependerá de los órganos receptores del animal-, pero no ya como meros estímulos, sino que como notas o contenidos que pertenecen a la cosa real misma perteneciéndole "en" y "por" sí misma, esto es, perteneciéndole "de suyo". Zubiri suele explicar esto diciendo que si para el animal el fuego calienta, para el hombre el fuego no solo calienta en la aprehensión, sino que "es" caliente, es decir, queda "en" la aprehensión como siendo "de suyo" caliente. En otras palabras, el fuego o el verde de la hoja son sentidos "en" la aprehensión, esto es, en el sentir mismo -antes de cualquier conceptualización- como siendo lo que son “en” y "por” sí mismos. Luego para Zubiri, a diferencia de la escolástica, la realidad no se identifica con lo existente extra-animam, con lo que posee un esse reale, sino que con un modo de ser de ese ente real que es el ser "de suyo", es decir, una formalidad en virtud de la cual la esencia y la existencia en sentido clásico le pertenecen a la cosa real como suyas. Esto significa, en un segundo paso, que para Zubiri, la realidad es un momento inespecifico que rebasa las determinaciones específicas de un ente singular. Esta formalidad de realidad reifica -le otorga el carácter de real qua real- no solo a los contenidos precisos de una cosa aprehendida, sino que a todos los contenidos que, por así decirlo, puedan entrar en su "ámbito" de realidad. En este sentido, lo que lo que aquí se llama realidad o "de suyo" constituye, al menos respecto del inteligir, es

4 Aunque la posición más madura de Zubiri en torno a la realidad como "de suyo" ya se encuentra suficientemente perfilada desde escritos como Sobre la Esencia (1962, 394-402), véase también el curso que Zubiri dio en 1966 Sobre la Realidad (25-27; 35-38), así como la formulación última en la trilogía de la Inteligencia Sentiente (1980-83), y especialmente en su primera parte, Inteligencia y Realidad (cf. IR: 57-60, 172-175). Para una breve introducción general a lo que Zubiri entiende por realidad, véase Secretan, Philibert 2011.

5 Esta expresión es clave en la filosofía madura de Zubiri y hace referencia a su noción de realidad. Que algo sea real significa que algo sea "de suyo" lo que es. De suyo significa, también, "en propio", es decir, que algo sea en propiedad lo que es o "en" y "por" sí mismo. Zubiri piensa que este carácter es dado en la aprehensión primordial o en el sentir primario del hombre antes de cualquier conceptualización. Aunque es imposible entrar en esto aquí, este carácter -según Zubiri- no se confunde con el de existencia. Para este aspecto fundamental de la filosofía de Zubiri, véase Espinoza Lolas, Ricardo 2002. 
decir, katà logón -y análogamente a la distinción entre ser y ente en Heidegger- un ámbito "trascendental" y "abierto" que rebasa o excede los contenidos de un singulum determinado. Para intentar esclarecer esta cuestión fundamental, Zubiri en ocasiones usaba la metáfora de un campo gravitatorio producido por una masa determinada. Es indudable, en este caso, que el campo gravitacional no es "algo" al modo en que lo es la masa que lo produce, como tampoco cabe pensar en ese campo de fuerzas separadamente de la masa de la cual emerge; sin embargo, es un hecho constatable que esa fuerza gravitatoria imperceptible, que es abierta por la masa, interactúa con otras masas que entran en su campo. Pues bien, aceptando las limitaciones obvias de la analogía, puede decirse que la realidad para Zubiri, aunque no es "algo", sí es un carácter intrínseco a la cosa que, al menos respecto a la inteligencia, se distingue de ella constituyendo un campo o ámbito de realidad trascendental que excede las determinaciones específicas del singular dado, y que sirve de horizonte en que todos los nuevos contenidos, ya sean reales o libremente fingidos (ficcionales), vienen a incardinarse o a realizarse. Por último, es necesario decir que, según Zubiri, esta formalidad no es algo a lo que primariamente se acceda por medio de un discurrir conceptual, sino que es una formalidad fisicamente sentida en la impresión de realidad. No se trata por ello de algo "construido" o meramente "puesto" por la inteligencia, sino que es una formalidad a su modo física (es decir, no-conceptiva) "dada" en la impresión de lo real.

Ahora bien, dicho esto, ¿qué entiende Zubiri por irreal? Consideremos en primer lugar la distinción recién trazada entre el momento individual de los contenidos y el momento inespecífico, la formalidad de realidad, que por su carácter eminentemente abierto, reifica -le otorga el carácter de realidad- no solo a los contenidos de la cosa real aquí y ahora aprehendidos, sino que a todos los contenidos que puedan advenir o alojarse en esa formalidad. En virtud de esta distinción entre contenidos y formalidad, y en razón del carácter decurrente y sentiente del inteligir humano, Zubiri observa que es posible y, de hecho, es necesario en vistas a poder experienciar lo que serían las cosas en la realidad, esto es, para que el vivir nuestro sea precisamente un vivir humano, es necesario -repetimos- llevar a cabo un proceso de “desrealización”. Según este proceso, se nos dice, se anularían o suspenderían los contenidos aprehendidos en una determinada impresión, pero conservando la formalidad de realidad, físicamente sentida, como un ámbito huero o vacío en el que es posible, luego, libremente alojar, configurar o realizar nuevos contenidos. Se trata, en este sentido, de "construir" los contenidos, aunque, insiste Zubiri, no la realidad -la formalidad inespecífica- en la que

6 Esta distinción, cambiando lo que hay que cambiar, es análoga a la diferencia ontológica realizada por Heidegger entre 'ente' y 'ser'. El 'ser' no es algo al modo del ente, pero tampoco es una nada. Es una dimensión del ente que comparece en tanto que es objeto de la comprensión (Verständnis) del Dasein. De una manera similar, el momento inespecífico de realidad es una dimensión trascendental de lo real que, perteneciéndole de suyo a la cosa, se manifiesta en el sentir intelectivo. Acerca de la relación entre el pensamiento de Zubiri y Heidegger, véase la valiosa compilación de artículos publicados por Nicolás M., Juan-Antonio y Espinoza Lolas, Ricardo A., Zubiri ante Heidegger, 2008. 
estos contenidos se incardinan. Por ello, piensa Zubiri, se entiende que el hombre para vivir como tal, es decir, para decurrir entre las cosas percibiéndolas, imaginándolas, pensándolas, necesariamente ha de distanciarse de ellas (toma de distancia que el animal, preso del estímulo, no puede realizar) de modo que, en un segundo momento, pueda volver sobre ellas construyendo o figurándose en cierta forma su contenido ${ }^{7}$. Así, para decirlo de una vez, lo irreal, en Zubiri, consistirá precisamente en las diversas realizaciones o figuraciones -Zubiri las llama también simples aprehensiones- que hacemos de lo real en un intento por percibir, fingir (imaginar) o conceptuar lo que las cosas "serían" en ese ámbito previamente abierto, y físicamente sentido, en que nos ha instalado la impresión sensible de lo real mismo. En palabras de Zubiri:

La irrealidad es el modo des-realizado de estar en "la" realidad. Es el primer momento de la irrealidad. Según este momento lo irreal envuelve "la" realidad. Primero, la envuelve formalmente: sólo puede ser irreal estando en "la" realidad desrealizadamente, esto es, sin que ésta tenga forzosamente un contenido determinado. Y segundo, la envuelve físicamente: en lo irreal, "la" realidad es "la" realidad que físicamente aprehendemos en la aprehensión primordial de cualquier cosa real. "La" realidad no es un concepto o una idea o algo semejante, sino que es la física dimensión campal de las cosas reales. Es la misma "realidad física" de este paisaje, de esta piedra, o de este prado, es esta misma realidad física, digo, la que se constituye campalmente en toda simple aprehensión de cualquier índole que sea: en un centauro "la" realidad aprehendida es la misma que en esta piedra. Lo que no es lo mismo es el contenido. La simple aprehensión no prescinde de "la" realidad como suele decirse secularmente, sino que la envuelve formal y físicamente como realidad sin contenido propio (Zubiri 1982: 93).

De nuevo, aquí, quizás tenga sentido volver retrospectivamente nuestra mirada hacia el pensamiento escolástico. Lo irreal para Zubiri no es simplemente algo que carezca de realidad (en el sentido de existencia) o que se oponga sin más a la realidad. Primero, esto no puede ser en el sentido en que lo entendió la escolástica, es decir, como un nihilum existentiae, porque a lo sumo lo que habría que decir es que lo irreal, una quimera, es algo que más bien carece de un tipo de existencia, esto es, de una existencia real o actual. Segundo, porque para Zubiri evidentemente algo irreal tendría una modalidad de existencia -y también una esencia-sui generis, esto es, una existencia y una esencia irreales. Tercero, y aquí reside también la gran originalidad del pensamiento zubiriano, porque si se dice que el centauro posee una existencia y una esencia irreales, esto solo puede ser así porque aquellos contenidos - tanto la esencia como la existencia- han sido libremente realizados o configurados en el ámbito de la realidad físicamente sentida,

7 Digo en cierta forma. En efecto, esta afirmación podría tomarse en el sentido de que la inteligencia tras tomar distancia de la cosa volvería por o tras ella "construyéndola", esto es, inventando arbitrariamente sus contenidos. Zubiri rechaza esto explícitamente. Aunque conocer las cosas en el campo de realidad que abre la formalidad siempre supone una libre construcción (realización) de su objeto, esta construcción no es ciega o arbitraria, sino que es guiada por lo dado en la aprehensión primordial. Cfr. $I L$, op. cit., cap. V-VI. 
aunque, por así decirlo, vaciada de sus contenidos "reales". Por eso puede concluirse que tanto una cosa real - esta mesa- como una cosa irreal -el número tres o Macbethse insertan en la misma formalidad de realidad, numéricamente la misma, en la que la aprehensión primordial de cualquier cosa real nos ha instalado y en la que, de hecho, somos retenidos siempre mientras haya decurso vital. Es interesante notar aquí que, a la luz de las tesis sostenidas por Zubiri, lo irreal, en último término, no es pensado ni como un mero objeto o ítem ideal que estuviera siendo meramente animado por la intencionalidad de la conciencia, ni tampoco - es obvio- como una cosa física, sino que como "cosa libre". "Lo irreal es pues cosa libre, por tanto cosa creada. La creación es creación no de la realidad sino de su contenido en ella; bien entendido, una realización libre. Si se quiere hablar de ideas [...] diré que crear no es dar realidad a mis ideas, sino que es justamente lo contrario: es dar mis ideas a la realidad" (Zubiri 1982: 95) ${ }^{8}$. Terminemos este apartado señalando brevemente que Zubiri distingue distintos modos de lo irreal según la forma en que libremente se realizan los contenidos en la realidad. Estos modos en Inteligencia y Logos son tres: percepto, ficto y concepto ${ }^{9}$. El percepto es el primer modo de actualizar "desrealizadamente" lo real. Una vez aprehendidos los contenidos dados en la impresión de "esta" cosa real, se prescinde del hecho de que le pertenezcan a "esta" cosa real que está delante de mí, es decir, los abstraemos del singular concreto. "Es el 'esto' de la cosa en cuanto mero término de percepción" (Zubiri 1982: 97). El verde de esta hoja particular pasa a ser las notas o contenidos generales ("esto" = verde), prescindiendo de si se instancia en esta o aquella hoja. En segundo lugar, el ficto, o la ficción, consiste en desrealizar el "esto" previamente reducido por el percepto, pero esta vez en la línea de la configuración de sus notas (el "cómo"), es decir, se deja ahora en franquía la sistematización o articulación precisa de las notas aprehendidas para poder libremente realizar nuevas sistematizaciones de las notas. Yo puedo, por ejemplo, deconstruir las notas aprehendidas en un rostro, ya previamente reducidas en el percepto, para reconfigurarlas, luego, al modo de un retrato cubista. En tercer lugar, es posible también actualizar desrealizadamente la configuración ya obtenida de lo real, el percepto y el ficto, aunque esta vez para intentar libremente fijar las notas esenciales, esto es, el "qué" de lo real, que sería precisamente lo que llamamos “concepto". Tanto el percepto, el ficto como el concepto son aquí modos de lo irreal, y por tanto, realizaciones libres de lo que lo real "sería" en la realidad como ámbito transcendental abierto.

$8 \quad$ Nótese que en lo que respecta a la relación entre lo irreal y la libertad, Antonio MillánPuelles, si bien partiendo de una concepción muy distinta del objeto ideal y de la realidad, sostiene ideas similares a las de Zubiri en este punto. Cfr. Millán-Puelles, Antonio. Teoría del Objeto Puro. Madrid: Ediciones Rialp, 1990.

9 Zubiri no siempre usó las mismas categorías para referirse a los modos de lo irreal. En El Hombre: Lo Real y lo Irreal (1967), por ejemplo, menciona otras: la ficción (equivalente al ficto), el espectro y lo ideal (equivalente al concepto). He preferido, sin embargo, utilizar aquí los modos de lo irreal que corresponden a Inteligencia y Logos (1982) (cfr. IL 96-101), ya que son los términos definitivos que fijó Zubiri y reflejan su pensamiento más maduro. 


\section{La ficción y el arte como modo de lo irreal}

Intentemos, en segundo lugar, sistematizar y profundizar un poco más las cuestiones tratadas, pero teniendo ahora en vista exclusivamente ese modo particular de lo irreal que es la ficción, y de modo general, el arte ${ }^{10}$. La gravedad de toda ficción, piensa Zubiri, reside en que ésta - pensemos en Don Quijote o en Macbeth-no es simplemente un ente de razón que no tuviera nada que ver con la realidad, como tampoco sería un contenido meramente intencional de mi conciencia, algo puramente mental y subjetivo, sino que, más bien, es una libre realización de la inteligencia humana -y no solo de mi razón ${ }^{11}$ que se realiza en el ámbito físico de la realidad como formalidad abierta. "La gravedad de la ficción le viene precisamente de que siendo una ficción desde el punto de vista de su contenido, sin embargo ese contenido está inscrito dentro del carácter físico y archirreal del momento de realidad" (Zubiri 1967: 29). En virtud de esto, Zubiri dirá que lo irreal -y por ende aquí la ficción- será "algo" realmente irreal, o lo que es lo mismo, algo irrealmente real ${ }^{12}$. La ficción, de este modo, y todo aquello que denominamos arte, sería un objeto particular, un objeto fingido - particularmente a través de fictos y conceptos- que sería strictu sensu una cuasi-creación. En efecto, sería, en cierto modo, una "creación" porque el hombre entero, según su experiencia intelectiva y sentiente de la realidad, libremente forja en ese ámbito físico los contenidos de su ficción. Pero, por otra parte, resulta claro que solo es una cuasi-creación ${ }^{13}$, porque "la" realidad no

10 Para la elaboración de este apartado se ha tenido en cuenta, de un modo general, un puñado de valiosos trabajos sobre el problema de la estética y del arte en Zubiri: Niño Mesa, F 1983; Simonpietri 1999 y Silvestre 2008. Del volumen editado por Diego Gracia, Ética y Estética en Xavier Zubiri (1996), nos han resultado muy útiles las consideraciones hechas por Germán Marquínez Argote en su artículo 'Literatura y Realidad: Zubiri y García Márquez'.

11 Para Zubiri la razón es solo un momento de la inteligencia humana, es decir, de la inteligencia sentiente. La inteligencia, en este sentido, ocupa "un volumen decisivo y fundamental en el hombre" (Zubiri 1967: 65), que no se reduce al momento racional. Zubiri, en efecto, radicalizando los intentos husserlianos y heideggerianos de ampliar la noción de logos (es decir, del logos predicativo), sostiene que ya el sentir mismo nos instala en la formalidad abierta e inespecífica de la realidad, constituyéndose por tanto como un sentir intelectivo. Es decir, el sentir humano sería en el mismo acto de aprehensión sentiente un acto intelectivo (aunque no racional o teórico), según el cual los contenidos sentidos quedarían aprehendidos como reales (y no como meros estímulos para una respuesta). Ésta es la novísima concepción de la Inteligencia Sentiente zubiriana, en la cual el filósofo distingue tres modos: aprehensión primordial, logos y razón. Sin embargo, una correcta determinación de estas cuestiones supera por mucho lo que aquí nos hemos propuesto. Cfr. acerca del sentir intelectivo, Inteligencia y Realidad, cap., III-IV.

12 Cfr. Zubiri, Xavier, 1982, op. cit., 95.

13 Aunque por razones filosóficas distintas a las esgrimidas por Zubiri, Husserl también le otorga al objeto estético o artístico el estatuto de "quasi-existente" [gleichfam-feiend]. Cfr. Ideas $I, \S 111$. Gran parte de la estética fenomenológica posterior desarrolla de distintas maneras esta poderosa intuición del maestro alemán. 
es nunca creada, sino que es dada sentientemente en la impresión como formalidad. Zubiri, así, ha pensado una filosofía en la que la ficción, como modo de lo irreal, se integra con lo real, volviéndose un momento imprescindible del decurrir humano a través de las cosas. Por eso, el hombre solo es capaz de atenerse a las cosas, es decir, de experimentarlas y conocerlas por medio del rodeo imprescindible de lo irreal y de la ficción. En este sentido puede decirse que el hombre es el único animal que, para poder estar en la realidad de las cosas ha de aprender a desenvolverse en lo irreal, y de un modo eminente, también, en la ficción que es la obra de arte, ya que a través de ella, el hombre -inserto en "la" realidad-no hace sino experienciar y pensar lo real. Esto quiere decir que el hombre no forja una ficción (o cualquier cosa irreal) simplemente porque tenga la capacidad de hacerlo -lo que es cierto-, sino porque además está forzado o exigido a hacerlo. Y esto por una razón doble. Primero, porque el hombre al figurarse por medio de irrealidades lo que son las cosas, no hace sino "estar en la realidad", de modo que lo irreal, y específicamente la ficción y el arte, se transforman en una vía de acceso que "nos orienta a la realidad" (Zubiri 1967: 125). Segundo, porque no solo se figura él qué son las cosas, sino que haciéndolo se "figura" a sí mismo, esto es, se "autoconfigura". Lo irreal, por ello, -y de un modo paradigmático las ficciones- se vuelve un modo de experienciar y probar lo que en cada caso somos nosotros mismos:

Las ficciones más ficticias, los conceptos más alejados de la realidad, dejan, evidentemente, su impronta en el ser sustantivo del hombre. Y sobre todo, le dejan en aquella dimensión y en aquel momento en que tenemos en cuenta la experiencia con nosotros mismos. El hombre, efectivamente, se figura ser de una cierta manera y hace la experiencia de sí mismo. Y esa experiencia de sí mismo es, a última hora, el eje cardinal de toda la integración de lo real y de lo irreal. Esa experiencia es estrictamente creadora. Por lo menos, cuasi-creadora. Creadora, porque no es algo dado sino hecho. Pero nada más que cuasi-creadora porque es una experiencia. Una experiencia en la cual lo creado no es un ens rationis, sino que es precisamente un ens hominis, en que el hombre desempeña una función de probación real y física respecto de sí mismo y de su propia realidad (Zubiri 1967: 197).

\section{Un caso literario: la concepción de la fantasía en J. R. R. Tolkien}

Para terminar, quisiéramos intentar reconducir lo hasta aquí expuesto en esta breve exposición -a partir de la obra filosófica de Zubiri- hacia algunos aspectos que consideramos centrales tanto en relación con la actividad productora (poiética) como receptora (estética) de la obra de arte. Para estos efectos tendremos en cuenta algunas de las notables reflexiones que J. R. R. Tolkien realiza en su ensayo Sobre los cuentos de hadas $^{14}$, al cual pertenece el fragmento que dispusimos como epígrafe a este artículo.

14 El ensayo se puede encontrar en Tolkien, J. R. R., Los monstruos y los críticos y otros ensayos. Buenos Aires: Editorial Planeta de Agostini, 2008. El título original del ensayo 
En primer lugar, quizá sea pertinente aclarar que si bien Tolkien aborda en esa famosa charla una forma particular de género que él denomina "fantasía", y que encuentra su mayor exponente en los cuentos de hadas, muchas de sus reflexiones, como veremos a continuación, son también válidas para otros géneros artísticos, lo que -nos parece- le otorgaría un alcance universal a sus afirmaciones. En segundo lugar, y más específicamente, quisiéramos argumentar que gran parte de las intuiciones que Tolkien expresa a partir de su experiencia creadora pueden ser entendidas, esto es, justificadas metafísica y epistemológicamente desde la singular fenomenología propuesta por Xavier Zubiri. Y esto, como recién lo indicábamos, no solo en relación con los cuentos de hadas o con los mitos en general, sino que teniendo en vista la totalidad de las formas de creación artísticas. Vayamos por partes.

Tolkien distingue entre lo que él llama "Mundo primario" y "Mundo secundario" (con mayúsculas en el original). Mundo primario alude a la realidad singular y concreta que experimentamos como algo verificable, es decir, aquello que se realiza en un espacio y tiempo mensurables. Mundo secundario, en cambio, se refiere a la dimensión de lo fantástico, o más propiamente de la fantasía, concepto que alude, como el mismo autor lo señala, al término "irrealidad (o sea disimilitud con el Mundo primario) y liberación de la servidumbre del "hecho" observado." (Tolkien 2008: 170). Por otra parte, si bien es verdad que Tolkien está ocupando los términos 'fantasía' y 'mundo secundario' en un sentido muy acotado, que no puede identificarse con lo que nosotros hemos llamado ficción y arte (Tolkien, por ejemplo, opone el mundo de la fantasía al género del teatro ${ }^{15}$ ), consideramos que la descripción general que él realiza de estos mundos secundarios ilumina poderosamente el fenómeno universal de la obra artística, así como su vínculo con la realidad (Mundo primario), y su capacidad de manifestar o revelar la esencia de éste. Más aún, se trata, como señalaremos brevemente, de consideraciones que bien podrían plantearse como el correlato experiencial (según la experiencia creadora de Tolkien) de aquello que, desde una perspectiva metafísica, ha sido expresado por Zubiri.

Ahora bien, resulta interesante constatar que en la visión de Tolkien, si bien es imprescindible (i) distinguir con claridad el Mundo secundario (Tierra Media) del Mundo primario (Londres), estos mundos (ii) no pueden ser separados tajantemente, porque -como nos lo dice en la cita del epígrafe- o bien uno procede del otro o bien fluye hacia él. Así, por una parte, (i) es evidente que el creador (o sub-creador, como lo llama Tolkien) se ha liberado de la esclavitud del hecho positivo a través de lo que él llama una "voluntaria suspensión de la incredulidad" (willing suspension of disbelief; cfr. Tolkien 2008: 161). Suspensión que, salvando obvias diferencias, tiene, en nuestra opinión, una cierta similitud con la "suspensión de los contenidos" de la realidad que Zubiri llama “desrealización”. En efecto, ningún artista podría forjar o configurar su obra

era Fairy Stories (luego publicado con el título On Fairy Stories). Se trata de una charla leída por Tolkien en 1939 en la Universidad de St. Andrews, Escocia, en honor del poeta y recopilador de mitos y cuentos populares, Andrew Lang. Fue posteriormente publicada el año 1947.

15 Cfr. op. cit., pp. 172-173. 
de ficción (de la índole que sea), si primero no tuviera la natural capacidad humana de tomar distancia de la opresión o tiranía que le impone la impresión singular de 'esto', quedando así libre para reconfigurar esos contenidos según una nueva forma, esto es, según una determinada forma artística. En este sentido, es claro que cualquier índole de obra artística construye o se figura un mundo secundario de sentido (algo "irreal") que no se encuentra sin más en la realidad del mundo primario. Y esto es así indistintamente del soporte material en que se realiza la obra. Así, por ejemplo, la obra artística que llamamos cuadro, y que se actualiza en el acto de contemplación, no se identifica sin más con las capas de pintura, que constituyen, no obstante, su primera condición de posibilidad $^{16}$. Por eso quien verdaderamente contempla El Jardín de las Delicias de El Bosco, abre o realiza ante sí, y mientras perdure ese acto de contemplación, un ámbito de (ir)realidad ${ }^{17}$ que hace suyo -al igual como ocurre con la Tierra Media- a través de un proceso de genuina inmersión, que presupone aquel proceso de "desrealización" o de "suspensión de la incredulidad". En efecto, si no fuese así, es decir, si no mediase ese proceso de desrealización, quedaríamos inevitablemente presos de la inmediatez del estímulo sensorial, i.e., presos de las capas y colores superpuestos del óleo, o de una determinada articulación de sonidos o grafemas, o de un determinado volumen -cierta resistencia física- en el espacio. Sin embargo, nunca llegaría a emerger, a partir de ese sustrato puramente material, la obra artística en cuanto tal, esto es, la obra como un determinado mundo de sentido ficcional en el cual podemos ingresar y movernos libremente.

En segundo lugar, (ii) hecha esta clara distinción entre mundo primario y secundario, ambos autores son enfáticos en afirmar -cada uno desde su particular

16 El problema de cómo entender correctamente la articulación entre el sustrato material de la obra y la obra artística en sí misma constituye en nuestra opinión uno de las cuestiones más delicadas al interior de una teoría de la obra artística. La estética de cuño fenomenológico ha hecho importantes -y muy diversos- aportes a este respecto. Véase Cofré, J. O. Filosofía de la Obra de Arte. Enfoque Fenomenológico. Santiago de Chile: Editorial Universitaria, 1990, donde el autor realiza clarificadores estudios en torno al carácter fundacional de la aproximación estética de Husserl y su influencia en Roman Ingarden, M. Heidegger, Etienne Souriau, Mikel Dufrenne y J. P. Sartre.

17 Alfonso López Quintas ha desarrollado, a partir de la filosofía de Zubiri, una reflexión en torno a la obra de arte como "realidades ambitales", que funcionarían como objeto (usamos aquí la palabra en un sentido laxo, no "cósico") de un "encuentro" que instaura una forma de relación de participación activo-receptiva. Cfr. López Quintas, Alfonso. "La racionalidad propia del arte. Creatividad y acceso a lo real", en Realitas III-IV. Trabajos del seminario Xavier Zubiri, Madrid: Sociedad de Estudios y Publicaciones, 1979. En general el desarrollo de López Quintas, que a la larga no es más que una reflexión desde Zubiri, es muy pertinente para entender cómo la experiencia que realizamos de la obra, tanto la del subcreador como la del espectador que la re-crea, es una en la cual nos inmergimos o sumergimos en un "campo de realidad" del cual hacemos, a su modo, una experiencia de intuición sensible, esto es, una experiencia en la que la ficción se nos "presenta" efectivamente como algo cuasi-real. 
disciplina ${ }^{18}$ - que la experiencia que podemos hacer de un determinado mundo de ficción (y utilizo aquí la expresión 'ficción' en un sentido más amplio que el que le asigna Tolkien al término 'fantasía') es de suyo inseparable de la experiencia de la realidad o del mundo primario del que procede. Y esto, a su vez, en un sentido doble. En primer lugar, porque -como nos señala Tolkien desde una perspectiva material de los contenidos- "la Fantasía se saca del Mundo Primario" (Tolkien 2008: 179), del mismo modo como un buen artesano saca de las propiedades de la arcilla, la vasija o la cuchara que, en cierto modo, estaba ya encerrada en ésta. Análogamente, Zubiri, aunque esta vez desde una consideración más metafísica (véase nota 20), nos dirá que la ficción, por más fantasiosa que sea, necesariamente realizará o fingirá sus contenidos de ficción en la formalidad de realidad en la que el hombre siempre está y decurre vitalmente. Por ello dirá Zubiri, tal como señalábamos más arriba, que la realidad -i.e., la formalidad de realidad-con la que se presenta un color, una piedra o un centauro es numéricamente la misma, aunque evidentemente los contenidos (aquí, nos referimos tanto a la esencia como a la existencia) no lo sean. La esencia y la existencia de este paisaje que tengo delante de mí son reales; en cambio, la esencia y la existencia de Tierra Media son irreales. Y esto, por una parte, quiere decir que desde la perspectiva de Zubiri, Tierra Media sí posee un modo positivo de existencia (pues no ostenta un carácter puramente carencial como sostendría la escolástica), en la medida en que se apoya en la formalidad física de realidad, aunque es evidente que esa modalidad de existencia (irreal) no sea, ni será jamás, la del libro que sostenemos en nuestras manos. Por otra parte, de este hecho también se colige que la rigurosa experiencia que como lectores o espectadores podemos hacer de algo irreal, aun cuando posea la autonomía de una ficción verdadera, jamás podrá separarse o desvincularse completamente de la experiencia que en todo momento estamos haciendo de lo real (por ejemplo, el volumen físico que tengo en mis manos y los grafemas negros que veo inscritos en sus páginas). En efecto, una, la ficción de sentido, es en la línea de la realidad deudora

18 En efecto, Tolkien nos habla desde la perspectiva de su experiencia como creador. Esta experiencia se mueve eminentemente en el plano material de los contenidos de lo real (plano óntico). En este sentido, el subcreador toma elementos de la realidad y los reconfigura según una forma que no está presente en la realidad, pero que adquiere cierto modo de existencia en el reino de fantasía. La reflexión de Zubiri, en cambio, asumiendo esas consideraciones fácticas, tiene una impronta metafísica, puesto que lo que el filósofo vasco quiere señalarnos es que la ficción (y todo lo irreal) procede de la realidad, pero en el sentido de que es la "formalidad" inespecífica de la realidad la que se experiencia como "ámbito", "campo" u "horizonte" en la cual se realiza o construye la ficción. De este modo, no solo los contenidos de la ficción proceden de la realidad (primaria), sino que ellos mismos están, también, "montados" sobre o en la realidad, pero ahora en tanto que formalidad inespecífica fisicamente sentida en la aprehensión. Esta explicación de cuño fenomenológico-metafísico (véase más arriba páginas 5-6), aunque prima facie no resulta fácil de asimilar, nos parece que justifica adecuadamente esa experiencia universal, según la cual lo obrado en la obra artística adquiere una consistencia "cuasi-real" que, de hecho, pareciera comportarse, como ya advirtiera Aristóteles en la Poética (1459a, 20), como un ser vivo. 
de la otra, la cosa-libro. Es decir: es la misma cosa física, el libro, el paisaje, o mejor aún, toda mi kinesis corporal como vector de instalación en el mundo real ${ }^{19}$, la que dejándome instalado en la realidad formal y trascendental, que ha sido abierta a través de la intelección sentiente de esa misma cosa de cuerpo presente (por ejemplo, la cosaahí libro), me habilita para figurarme mundos o construcciones ficcionales de sentido que, sin embargo, no pueden sino estar "montados"-como si se tratara de un escenario metafísico-sobre esa misma formalidad. Pero, en segundo lugar, no solo sería necesario afirmar la inseparabilidad de lo irreal respecto de lo real en virtud de que una procede de la otra, sino que, también, y en esto Zubiri, Tolkien y Guardini (entre muchos otros) coinciden plenamente, la obra, una vez forjada, tiene la asombrosa capacidad de revertirse sobre la realidad del mundo primario, iluminándolo con la luz esencial de su forma o esplendor artístico, para así volverse un principio de inteligibilidad de lo real. En otras palabras, tal como nos señala Tolkien, a través del lente de la ficción aprendemos a ver con la "visión prístina" de quien ve originariamente las cosas según lo que ellas son realmente, puesto que su cristal no nos aleja de la realidad, sino que amplificándola, nos la manifiesta en su esencia verdadera:

Al forjar a Gram se descubrió el temple del hierro; con la creación de Pegaso se ennoblecieron los caballos; en los Árboles del Sol y la Luna se manifiestan gloriosos el tronco y las raíces, la flor y el fruto.

Y agrega enseguida:

Y es una realidad que los cuentos de hadas (los mejores) tratan amplia o primordialmente de las cosas sencillas o fundamentales que no ha tocado la Fantasía; pero esas cosas sencillas reciben del entorno una luz particular. Porque el narrador que se permite ser "libre" con la Naturaleza puede ser su amante, no su esclavo. Fue en los cuentos de hadas donde yo capté por vez primera la fuerza de las palabras y el hechizo de cosas tales como la piedra, la madera y el hierro, el árbol y la hierba, la casa y el fuego, el pan y el vino (Tolkien 2008: 179-180).

De este modo - de acuerdo con Tolkien- cuando la ficción es genuina ficción y cuando el acto contemplativo nos sumerge creativamente en ella, ocurre que aprendemos a "ver" irrealmente las cosas reales, según esa peculiar forma de "encuentro" o "juego receptivo-activo" en la que nos inmergimos al realizar -unas veces de golpe, otras, gradualmente- la experiencia creadora (o receptora) de la obra.

19 Es evidente que, aunque la descripción de Zubiri pueda parecer a ratos algo estática al hablar de la aprehensión de "una" piedra o "un" paisaje, en último término esa aprehensión primordial debe ser entendida -en Zubiri- desde la kinesis del cuerpo como totalidad. En nuestra opinión, esta aproximación puede fácilmente ponerse en diálogo con la noción del "esquematismo corporal" desarrollada por Merleau-Ponty en su Fenomenología de la Percepción. Cfr. Cap. III, 'Espacialidad del propio cuerpo y la motricidad'. 
Por último, si bien es evidente que el lenguaje de Zubiri carece de la gracia y del sentido de la intuición artística que muestra Tolkien, creemos que su concepción de lo irreal, y más propiamente de la ficción, ratifica y fundamenta lo aquí expresado por el autor inglés. En efecto, Zubiri piensa que el hombre es el único animal que para ser lo que verdaderamente es, es decir, para poder hacer verdaderamente la experiencia de lo real debe necesariamente dar el "rodeo" de lo irreal -y paradigmáticamente aquí, de la obra artística. Pues solo figurándose lo que las cosas "podrían ser", es decir, moviéndose libremente en el campo de (ir)realidad y de sentido ficcional que posibilita lo irreal y, particularmente para nosotros, las obras de arte, puede el hombre alcanzar un verdadero "encuentro" con aquello con lo cual siempre está, pero que, paradójicamente, se le oculta tenazmente ${ }^{20}$, esto es, la realidad misma "de" las cosas o, si se quiere, las cosas "en" su realidad. Concluyamos volviendo nuestra reflexión hacia aquella particular, pero al parecer universal experiencia, a la que tanto Tolkien como Guardini se refieren. A Tolkien le parece evidente que el mito como forma de ficción "proceda de la Realidad o fluya hacia ella", ya que en definitiva es necesario - nos dice- "que la obra forme parte de esa realidad". Afirmación que coincide maravillosamente con la idea de que la obra de arte, como expresa Guardini, abre un espacio o ámbito en que podemos entrar, volviéndonos realmente de un lugar a otro, como quien inspecciona un jardín lleno de recovecos. En esta misma línea creemos que la filosofía de Zubiri, si bien requiere un esfuerzo inicial no menor de compenetración, constituye un marco teórico de inigualable riqueza a la hora de pensar cuestiones como el estatuto ontológico de lo

El ocultamiento (del ser) de las cosas a manos de la técnica ha sido un tema recurrente en la reflexión filosófica del s. XX desde Heidegger, pasando -entre otros-a través de la Escuela de Frankurt. Zubiri, hasta donde sabemos, no tuvo un particular interés por los pensadores de dicha Escuela (Adorno, Horkheimer, Benjamín, Marcuse), pero ciertamente hubiera secundado en lo principal, y desde su propia reflexión en torno a la realidad, la crítica al afán desmesurado de dominio y control técnico de la racionalidad moderna que realizan tanto Heidegger (de una influencia gravitante para Zubiri) como estos pensadores. En este sentido, desde la óptica de Zubiri, es claro que el verdadero encuentro con la realidad de lo real (tanto al nivel del logos como en el de la marcha intelectiva de la razón) puede verse ocultado, o seriamente limitado, por un lenguaje y una racionalidad técnica desmedida que opaque, total o parcialmente, la amplitud de los diversos cánones y de los diversos métodos de la razón (así el canon o medida emocional y el canon metafórico son distintos, pero no inferiores, del canon lógico-formal). Acerca del concepto mismo de 'canon' y el concepto afín de 'mentalidad', como modos diversos de la razón para avanzar en pos de lo real en su dimensión de profundidad mundana, véase, Zubiri, Inteligencia y Razón: para los conceptos de 'canon', 57-59; para 'mentalidad' y 'mentalidad científica', 'poética', 'metafísica', 'política', etc., 149-155. En general, el tercer volumen entero de la trilogía de la Inteligencia Sentiente (IS), Inteligencia y Razón (IRA) es sumamente valioso a este respecto. Por otra parte, es interesante notar que Tolkien piensa que el gran peligro que nos impide ver las cosas "renovadamente" en su carácter originario es la monotonía y legalidad que acompaña nuestro "afán de posesión"; afán de posesión por el cual, acostumbrados a tener a nuestra disposición las cosas, dejamos de prestarles atención. Cfr., Tolkien, op. cit.: 178. 
irreal como "cosa libre", así como el modo particular en que se inserta la obra de arte en la realidad o la necesidad rigurosa que tiene el hombre de aprender a vivir en lo irreal -y paradigmáticamente en la ficción del arte- para poder estar en lo real mismo y, así, realizar, en definitiva, la experiencia de las cosas, de los otros y de sí mismo.

\section{Referencias bibliográficas}

Aquino, Tomás (1979), Comentario al "Libro del alma" de Aristóteles. Traducido y anotado por María C. Donadío Maggi de Gandolfi. Buenos Aires: Fundación Arché.

(2001), Suma de teología. Madrid: BAC, 5 vol.

Aristóteles (1974), Poética. Traducción de Valentín García Yebra. Madrid: Gredos.

Cofré, J. O. (1990), Filosofía de la Obra de Arte. Enfoque Fenomenológico. Santiago, Chile: Editorial Universitaria.

Espinoza Lolas, Ricardo (2002), "Algunas reflexiones sobre la "formalidad", el "de suyo" y el "prius", Xavier Zubiri Review, http://www.zubiri.org/general/ xzreview/2002/pdf/lolas_XZR2002.pdf

Guardini, Romano (1981), "La esencia de la obra de arte", Obras de Romano Guardini I. Madrid: Ediciones Cristiandad.

Gracia, Diego et al. (1996), Ética y Estética en Xavier Zubiri. Madrid: Editorial Trotta.

Merleau-Ponty, Maurice (1957), Fenomenología de la Percepción. Trad. Emilio Uranga. México, Buenos Aires: FCE.

Millán-Puelles, Antonio (1990), Teoría del Objeto Puro. Madrid: Ediciones Rialp.

Moya, Patricia. "La intencionalidad como elemento clave en la gnoseología del Aquinate". Pamplona: Cuadernos de Anuario Filosófico, 2000.

Nicolás M., Juan-Antonio; Ricardo A. Espinoza Lolas, edit. (2008), Zubiri ante Heidegger. Editorial Herder.

Niño Mesa, F. (1983), “Arte y Realidad en Zubiri”, Cuadernos de Filosofía Latinoamericana $\mathrm{N}^{\circ} 17$.

Quintas-López, Alfonso (1976-1979), “La racionalidad propia del arte. Creatividad y acceso a lo real", Realitas III-IV. Trabajos del seminario Xavier Zubiri. Madrid: Sociedad de Estudios y Publicaciones.

Secretan, Philibert (2011), "El concepto de realidad en la filosofía de Xavier Zubiri”, Guía Comares de Zubiri. Comares Editorial, pp. 329-350.

Silvestri, Ricard (2008), "De la «pulcritud» en las denominadas nuevas prácticas artísticas: Xavier Zubiri para el arte contemporáneo", Aisthesis. Pontificia Universidad Católica de Chile 44: 145-157.

Simonpietri, Fannie A. (1999), “¿Qué es el arte? en las 'Reflexiones sobre estética’ de Xavier Zubiri”, La Torre. Revista de la Universidad de Puerto Rico 11: 193-205. 
Tolkien, J. R. R. (2008), Sobre los Cuentos de Hadas. Buenos Aires: Editorial Planeta. Zubiri, Xavier (1980), Inteligencia Sentiente: Inteligencia y Realidad. Madrid: Alianza Editorial.

(1982 ), Inteligencia y Logos. Madrid: Alianza Editorial. (1983 ), Inteligencia y Razón. Madrid: Alianza Editorial. (1985), Sobre la Esencia. Madrid: Alianza Editorial. (1998), Sobre el Hombre. Madrid: Alianza Editorial. (2001), Sobre la Realidad. Madrid: Alianza Editorial. (2005 ), El Hombre: Lo real y lo Irreal. Madrid: Alianza Editorial. 